\title{
Economic analysis of wind-storage combined power station considering cooperative operation mode
}

\author{
Liu Peng ${ }^{1 *}$, Xiao Huixu ${ }^{2}$, and Qi Shiwei ${ }^{1}$, Han Siyu ${ }^{1}$, Zhang Zhipeng ${ }^{1}$, Yao Di ${ }^{1}$, Fu Mengdi $^{3}$ \\ ${ }^{1}$ Economic and Electrical Research Institute of Jilin Electrical Power Company of SGCC, Changchun, Jilin, China \\ ${ }^{2}$ State Grid Jilin Electric Power Co., Ltd., Changchun, Jilin, China \\ ${ }^{3}$ North China Electric Power University, Beijing, China
}

\begin{abstract}
In engineering construction, the accurate estimation of the investment cost can provide a reasonable basis for the formulation and decision-making of the construction scheme. In this paper, the wind-storage combined operation power station is taken as the research object, the investment cost estimation model is established, and the combined operation mode is analysed to obtain the annual power generation. Finally, according to the investment cost and annual power generation, the cost per unit of electricity model is established. In the past, wind farm and pumped storage power station are usually studied as two independent individuals, but in practical application, there are power conversion, regulation and control operations between them, which are interrelated and interactive. This paper regards the two as a whole and analyses their annual power generation under different cooperative operation modes. The research results of this paper can provide a theoretical basis for the preliminary cost estimation of engineering construction, so as to better determine the construction scheme of power plant.
\end{abstract}

\section{Introduction}

Wind energy is a clean and abundant renewable energy source. Wind speed varies randomly in time and space, and wind energy cannot be stored. The instability characteristic of wind power has a certain impact on the power grid and users who require stable power output. Therefore, it is necessary to seek reasonable peak regulation and energy storage configuration for making full use of wind energy.

Some scholars in the CIGRE pointed out that in order to gain the development of wind power, the peak regulation problem must be solved. At present, the main solutions for the problem are battery energy storage system(BESS), thermal power, gas and pumped storage power stations. The storage battery cannot meet the standby capacity requirement of China's current wind power installed capacity due to its high cost and small capacity. Thermal power cannot meet the flexibility requirements of peak regulation. China is short of gas resources, so it is not reasonable to allocate it as a reserve for wind power peak regulation. It can be said that pumped storage power station is the most economical, flexible and clean peak-regulating power source[1].

Wind and water power can be perfectly combined. In Norway, $99 \%$ of electricity is generated by hydroelectric power, and Denmark is focusing on wind power. When the electricity produced by the wind farm in Denmark is not available (as at night when electricity consumption is low), it is transmitted to the pumped storage power station in Norway through cables and lines laid on the ground, under the sea and in the air. The pumped storage power station raise water from the lower to the upper reservoirs by pumps. At peak times in Denmark, Norway's pumped storage power station open the gates and release water into a lower reservoir to generate electricity, which is then transmitted back to Denmark. It can be seen that pumped storage can realize the storage of wind power.

China's total amount of water resources, reserves and exploitable amount are ranked first in the world. Wind energy resources are abundant in China's three northern regions and southeast coastal areas. In Xinjiang, Inner Mongolia, Ningxia, Gansu and other places where water resources are relatively scarce, wind power peak regulation mainly relies on thermal power. The economy, flexibility and sustainability of thermal power peak regulation are issues that need to be considered. The rapid development of wind power in China is not coordinated with the slow development of peak regulation and energy storage configuration, which directly affects the utilization rate of wind energy and the on-grid power and economic benefits of wind farms.

As a kind of energy storage technology, pumped storage power station can not only provide stable power supply to the power grid, but also increase the operation efficiency of wind power and promote the development of China's wind power industry through the conversion and storage of wind power. Combined wind-storage power station combines the advantages of the two and leads the development trend in the future. Under the

\footnotetext{
Corresponding author: fumengdi@163.com
} 
condition of mature technology research, reasonable project investment calculation has become an important factor affecting the construction and development of wind-storage combined operation power station.

In this paper, the cost model of combined windstorage power station including construction cost and operation cost is established. Then it analyses the operation mode of wind-storage combined power station is analysed, the output of wind-storage combined power station under different operation modes is studied and the calculation method of annual power generation under different operation modes is proposed. Finally, this paper establishes the calculation model of unit electricity generation cost of the wind-storage combined power station.

\section{Analysis of total annual cost of electricity generation in combined operation power station}

In the early stage of project construction, the cost per unit of electricity generation is an important index for the comparison and decision of the construction scheme of wind-storage combined operation power station. On the basis of estimating the total investment of the project, the model of cost per unit of electricity generation is established to estimate the total investment and unit investment of the project, so as to improve the accuracy of the project investment and the correctness of the scheme selection. The total investment cost of windstorage combined operation power station includes construction cost and operation cost.

\subsection{Construction cost of wind-storage combined operation power station}

The total annual construction cost of the combined operation power station includes the cost of materials, wages, welfare and depreciation of fixed assets ${ }^{[2]}$, which can be expressed as (1).

$$
F_{c}=C_{m c}+C_{w w}+C_{a d c}
$$

where $F_{c}$ refers to the total annual construction cost of the combined operation power station, $C_{m c}$ refers to the cost of materials, $C_{w w}$ refers to the cost of wages and welfare, $C_{a d c}$ refers to the annual depreciation of fixed assets.

\subsubsection{The cost of materials and wage and welfare}

The cost of materials is calculated according to the installed capacity. Wind power plant and pumped storage power station are two main parts in the combined operation of wind - storage power station. Therefore, the cost of materials wind farm and pumped storage power station is calculated respectively according to the installed capacity of the two parts, and then the sum of the two parts is the material cost of the combined operation power station.

The cost of wages and welfare is calculated according to the quota standard of the combined operation power station and the current salary level of similar projects. The salary level is the average annual salary and welfare of each employee.

\subsubsection{The annual depreciation of fixed assets}

The annual depreciation of fixed assets can be expressed as (2).

$$
C_{a d c}=I_{O V F A} \times(1-\alpha) / M
$$

where $\alpha$ refers to residual rate, $(1-\alpha)$ refers to the formation rate of fixed assets, $M$ is the depreciation life, $I_{O V F A}$ is the original cost of fixed assets, which can be expressed as (3).

$$
I_{\text {OVFA }}=I_{F A}=I_{\text {toal }}-I_{L C}
$$

where $I_{F A}$ is investment in fixed assets, $I_{\text {total }}$ is the total investment, $I_{L C}$ is investment in current capitals, which is determined by the estimation method of fixed asset investment capital ratio.

By substituting Equation (3) into Equation (2), the expression of annual depreciation cost of fixed assets can be obtained as (4).

$$
C_{a d c}=\left(I_{\text {total }}-I_{L C}\right) \times(1-\alpha) / M
$$

By substituting Equation (4) into Equation (1), the expression for the total annual power generation cost of the wind-storage combined power station can be obtained as (5).

$$
\begin{aligned}
F_{c}= & C_{m c}+C_{w w}+C_{m e}+C_{o e} \\
& +\left[\left(I_{\text {total }}-I_{L C}\right) \times(1-\alpha) / M\right] \times(1-\gamma)
\end{aligned}
$$

\subsection{Operating cost of wind-storage combined operation power station}

The operation cost model of the wind-storage combined power station, as shown in Equation (6), is established by comprehensively considering the generation cost of the combined power station, the environmental benefit absorbed by the combined operation and the operation and maintenance cost, the spinning reserve cost of the system, and the purchase cost of peak regulation capacity ${ }^{[3]}$.

$$
F_{o}=F_{1}+F_{2}+F_{3}+F_{4}+F_{5}
$$

where $F_{o}$ refers to the comprehensive operation cost of combined operation power station, $F_{1}$ refers to the combined operation cost of the wind-storage power station, $F_{2}$ refers to the environmental benefit, $F_{3}$ refers to the rotation and reserve cost of the system, $F_{4}$ refers to the purchase cost of peak regulation capacity.

\subsubsection{The combined operation cost of the wind- storage power station}

The operation cost of the pumped storage unit only includes the cost generated when the unit switches between different working states, that is, the start-up cost of the generator when generating electricity and the startup cost of the motor when pumping water ${ }^{[4]}$. The combined operation cost can be expressed as (7). 


$$
F_{1}=\sum_{t=1}^{T}\left[k_{f} P_{f t}+c_{p} I_{p, h}^{t}\left(1-I_{p, h}^{t-1}\right)+c_{g} I_{g, h}^{t}\left(1-I_{g, h}^{t-1}\right)\right]
$$

where $k_{f}$ refers to the operation and maintenance cost of wind farm, $P_{f t}$ refers to the output power of wind farm at time $t, C_{p}$ and $C_{g}$ refer to the start-up cost coefficient of the pumped storage unit in the state of pumping and power generation, respectively, $I_{p, h}^{t}$ and $I_{g, h}^{t}$ refers to the binary integer variable of the pumped storage unit in the pumping state and the generating state at time $t$, respectively.

\subsubsection{The environmental benefits of wind-storage combined operation}

The new energy generation based on wind power and pumped storage can effectively reduce the on-grid power of thermal power units, reduce pollutant emissions, and produce certain environmental benefits. The environmental benefits can be expressed as (8).

$$
F_{2}=\sum_{t=1}^{T} k_{F} P_{f t}
$$

where $k_{F}$ refers to the environmental benefit coefficient.

\subsubsection{The spinning reserve cost of the system}

The large-scale integration of wind power into the grid increases the uncertainty of system. Therefore, more capacity needs to be reserved to deal with forecast errors and emergencies. The additional cost of spinning reserve can be expressed as (9).

$$
F_{3}=\sum_{t=1}^{T} k_{r}\left(P_{L t} L+P_{f t} F\right)
$$

where $L$ refers to the forecast error rate of loads, $F$ refers to the forecast error rate of wind power, $k_{r}$ refers to the coefficient of spinning reserve cost of the system, $P_{L t}$ refers to the load power at time $t$.

\subsubsection{The Purchase cost of peak regulation capacity}

Due to the random fluctuation of wind power, the adjustable capacity of the power system will decrease when the wind power is connected to the grid on a large scale, and it may cause difficulties in the load peak and trough periods. In this case, to ensure the safe operation of the power grid, it is necessary to purchase a certain capacity of peak regulation. The purchase cost of the peak regulation capacity can be expressed as (10).

$$
F_{4}=\sum_{t=1}^{T} k_{p}\left|P_{s t}\right|
$$

where $k_{p}$ refers to the coefficient of peak regulation capacity, $P_{s t}$ refers to the purchased peak regulation capacity at time $t$. We have:

$$
P_{s t}=P_{L t}-\left(\sum_{i=1}^{n} P_{f t}+P_{c t}\right)
$$

\section{Function and operation analysis of combined operation power station}

\subsection{Function mode of combined operation power station}

The purpose of establishing the wind-storage combined operation power station is to improve the utilization rate of wind energy. Under the premise of ensuring the stable, balanced and efficient operation of the power grid, the combined pumped storage power station will regulate as much wind power as possible and store the remaining wind power in the way of pumping water. The electric energy produced by the power station needs to be sold online, but sometimes it cannot meet the demand of load. Therefore, the combined wind-storage power station should be used as an output part of the whole power grid. It should be combined with conventional power plants to jointly bear the whole load system, and the control system will control the whole power grid, as shown in Fig. 1.

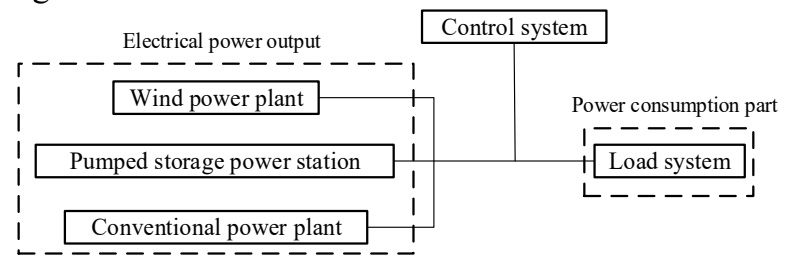

Fig. 1. Brief schematic diagram of wind-pumped storage combined operation power station.

The system load is fluctuant, which is reflected in the Cartesian coordinate system as a curve of the system load varying with time. The curve has peak and valley values, that is, the system load includes base load, waist load and peak load. The part below the minimum load horizontal line is called the base load, the part above the average load horizontal line is called the peak load, and the part between the minimum load and the average load is called the waist load.

\subsection{Analysis of operation mode of combined operation power station}

The output of a power station depends on the way it operates. European scholars took the lead in many explorations and practices on the feasibility and operation mode of wind-storage combined operation power stations ${ }^{[5]}$. This kind of combined operation power station is feasible. Literature [6] and [7] analyses and summarizes six operation modes, which can be divided into three categories according to whether the wind energy is connected to the grid during the operation of the combined operation power station.

\subsubsection{Electricity generated by wind power stations are connected to the grid}

In the first category, during the whole operation of the combined power station, the electricity generated by wind energy is connected to the grid. The maximum amount of electricity generated shall be guaranteed first, 
and the wind energy exceeding the grid-connection shall be stored through the pumping method of the pumping units in the pumped storage power station. See operation mode 1 and 2 for details.

Operation mode 1: According to the characteristics of random variation of wind speed in time and space, it is unsafe to directly input a large part of wind energy directly into the grid for the use of load system. Unstable wind energy will not only affect the safe operation of transmission equipment, but also may bring about the imbalance of power output and load demand. Therefore, direct wind energy input to the grid is limited to a permissible proportion, and $\beta$ is used to denote the maximum proportion of wind energy input to the grid. The load in this operation mode is jointly borne by wind power, hydropower and conventional power generation. The normal operation of the power grid needs to ensure the balance of electricity supply and demand, which can be expressed as $(12) \sim(15)$.

$$
\begin{gathered}
P_{\text {total }}(t)=P_{W F}(t)+P_{T B}(t)+P_{C P P}(t) \\
E_{\text {total }}(t)=E_{P P}(t)+E_{L S}(t) \\
P_{\text {total }}(t)=E_{\text {total }}(t) \\
E_{L S}(t)=\left[E_{L S}(t)\right]_{\text {base }}+\left[E_{L S}(t)\right]_{\text {waist }}+\left[E_{L S}(t)\right]_{\text {peak }}
\end{gathered}
$$

where $P_{\text {total }}(t)$ is the total quantity of all power supply at time $t ; P_{W F}(t)$ is the wind farm output at time $t ; P_{T B}(t)$ is the turbine output at time $t ; P_{C P P}(t)$ is the output of conventional power plants at time $t ; E_{\text {total }}(t)$ refers to all load demands at time $t ; E_{P P}(t)$ is the electric energy consumption of water pump at time $t ; E_{L S}(t)$ is the electric energy consumption of the load at time $t$. There are two types of operation.

(1) The electricity generated by wind power can meet the grid-connected capacity, i.e. $P_{W F}(t) \geq E_{L S}(t) \times \beta$.

Wind farm output: the sum of $\operatorname{ELS}(\mathrm{t}) \times \beta$ part and the electric energy consumed by water pump, which can be expressed as (16).

$$
P_{W F}(t)-E_{L S}(t) \times \beta=E_{P P}(t)
$$

When the water volume $V(t)$ is sufficient at the time $t$ of the upper reservoir, the $E_{L S}(t) \times(1-\beta)$ part of the load system is borne by the generator set of the pumped storage power station (hereinafter referred to as hydropower output). When $V(t)$ is insufficient, the $E_{L S}(t) \times(1-\beta)$ part of the load system is shared by the hydropower output and the conventional power plant. When $V(t)$ is less than the minimum water volume $V_{\text {min }}$ to drive the turbine, the $E_{L S}(t) \times(1-\beta)$ part of the load system is borne by the conventional power plant independently.

(2) Wind power generation is less than the gridconnected power, i.e. $P_{W F}(t)<E_{L S}(t) \times \beta$

Wind farm output $P_{W F}(t)$ is all used for gridconnection, and the $\left[E_{L S}(t)-P_{W F}(t)\right]$ part of the load system is jointly undertaken by hydropower output and conventional power plant, and the specific load and situation (1) are the same. It can be expressed by the following equation:

$$
\left\{\begin{array}{l}
\lambda\left[E_{L S}(t)-P_{W F}(t)\right]=P_{T B}(t) \\
(1-\lambda)\left[E_{L S}(t)-P_{W F}(t)\right]=P_{C P P}(t)
\end{array}\right.
$$

Where $\lambda$ represents the proportion of water and electricity output in the $\left[E_{L S}(t)-P_{W F}(t)\right]$ part of the load system. When $V(t)$ reaches $V_{\max }, \lambda=1$; when $V_{\min }<$ $V(t)<V_{\max }, 0<\lambda<1$; when $V_{\min }<V(t), \lambda=0$.

In the operation mode I, the output part of the windstorage combined operation power station is the generating unit in the wind farm and pumped storage power station, namely, the wind turbine and water turbine work to generate electricity. The calculation formula of the output of the two at time $t$ is as follows:

$$
\begin{gathered}
P_{W F}(t)=k_{W}(t) \cdot q_{W}(t) \cdot \mu \cdot \omega \\
P_{T B}(t)=\rho \cdot g \cdot k_{T B}(t) \cdot Q_{T B}(t) \cdot H_{T B}(t) \cdot \eta_{T B}(t)
\end{gathered}
$$

where $k_{W}(t)$ is the number of working wind turbines at time $t ; q_{W}(t)$ is the wind turbine power of a single wind turbine at time $t$, and its value can be obtained by combining the wind turbine power-wind speed curve and the wind speed-time curve interpolation. $\mu$ and $\omega$ are respectively the transmission efficiency and power generation efficiency of the wind turbine, and the wind wheel power-wind speed curve are provided by the manufacturer; $k_{T B}(t)$ is the number of working units of the turbine unit at time $t ; Q_{T B}(t), H_{T B}(t)$ and $\eta_{T B}(t)$ are respectively the flow rate, head and efficiency of a single turbine unit at time $t$.

Operation mode 2: it is similar to operation mode 1 , but the main difference is that when the water volume of the upper reservoir does not reach $V_{\max }$ at time $t$, that is, when $V(t)>V_{\max }$, no hydroelectric power is produced, and part $\left[E_{L S}(t)-P_{W F}(t)\right]$ of the load system is independently undertaken by the conventional power plant. When $V(t)=V_{\max }$, hydropower and wind power jointly bear the load system. Under this operation mode, the output calculation at time $t$ of the combined operation power station is the same as that of Mode 1, and it is more convenient than Mode 1 to predict the time of relative grid connection and disassembly of hydroelectric generating sets and conventional power plants respectively.

\subsubsection{None of Electricity generated by wind power stations are connected to the grid}

In the Second category, during the whole operation of the combined power station, the wind farm is independent from the power grid, so the power generation is not connected to the grid and is only used for pumping water. The load system is jointly undertaken by hydropower and conventional power plants. $\xi$ represents the proportion of hydropower output in the load system, and the following equation is established:

$$
\left.\begin{array}{c}
P_{W F}(t)=E_{p p}(t) \\
\xi \cdot E_{L S}(t)=P_{T B}(t) \\
(1-\xi) \cdot E_{L S}(t)=P_{C P P}(t)
\end{array}\right\}
$$


Operation mode 3: when the water volume $V(t)$ of the upper reservoir at time $t$ is greater than the minimum water volume $V_{\min }$ to drive the turbine, $0<\xi<1$, the hydropower output bears the load demand; When $V(t) \leq V_{\min }, \xi=0$, the conventional power plant undertakes the whole load system independently. In this operation mode, when the turbine is capable, the output of the water turbine will bear the load, and the amount of water pumped by the pump is determined by the generating capacity of the wind energy. Although the wind power does not participate in the grid connection, it belongs to the output of the wind-storage combined operation power station. Therefore, the total power generation of the combined operation power station includes all the power output of wind farm and water turbine, and the calculation of power generation is the same as Equations (18) (19).

Operation mode 4: the basic situation is similar to that of operation mode three, the difference is in the period when the hydropower output part is initially connected to the power grid. The upper reservoir needs to reserve a control capacity $V_{c}$, that is, the storage capacity to ensure that the hydropower station reaches the maximum load $\left[E_{L S}(t)\right]_{\max }$ within a given time $t_{c}$. In the process of $V(t) \leq V_{c}$ and the storage of upper reservoir, the hydropower station is separated from the power grid. When $V(t)=0$, the hydropower output bears all the load demand. This method is easy to predict the time of connecting and disconnecting the power grid, and the calculation method of the power generation of the combined operation power station is the same as the operation mode 3 .

\subsubsection{Wind power generation is connected to the grid in part of the process}

In the third category, in the whole operation process of the combined power station, the wind farm is not completely independent from the power grid, and the electricity generated by the wind energy is connected to the grid in part of the process. The following two modes of operation are special cases of mode two.

Operation mode 5: in the process of water storage in the upper reservoir, the hydropower station is disconnected from the power grid, the load system is independently undertaken by the conventional power plant, and all the energy generated by the wind energy is used for water pumping. This process is expressed in Equation (22). When the upper reservoir is empty, the load system is jointly undertaken by wind power and hydropower, which is the same as operation mode two. In this case, wind power participates in grid connection.

$$
\left.\begin{array}{l}
P_{T B}(t)=0 \\
P_{W F}(t)=E_{p p}(t) \\
E_{L S}(t)=P_{C P P}(t)
\end{array}\right\}
$$

Operation mode 6: In the process of water storage in the Upper Reservoir, the hydropower station is disconnected from the power grid, wind power participates in the Internet connection, and the load system is jointly undertaken by conventional power plants and wind farms, that is, $\lambda=0$ in Equation (17); When the upper reservoir is empty, the load system is independently undertaken by the hydropower station, and all the wind power is used for pumping water. This process is expressed by the equation as follows:

$$
\left.\begin{array}{l}
P_{C P P}(t)=0 \\
P_{W F}(t)=E_{p p}(t) \\
E_{L S}(t)=P_{T B}(t)
\end{array}\right\}
$$

In the operation process of these two modes, both the wind farm of the combined wind-storage power station and the generating units of the pumped storage power station participate in the generation work. The power generation of the power station at time $t$ is also the sum of the output of the wind turbine and the hydraulic turbine, and the calculation formula is the same as that of Method 1.

\section{Estimation model of unit electricity generation cost of combined operation power station}

Through the analysis of the six operation modes, it can be seen that the wind-storage combined operation power station is an output part of the power grid. Under different operation modes, both the wind farm and the generating units in the pumped storage power station participate in the power generation work, and the power generation at time $t$ is the sum of the output of the wind turbine and the hydraulic turbine.

Equations (18) and (19) for calculating the output of wind turbine and water turbine are the electric quantity at a certain moment, and each variable is a function of time $t$. Integrate $P_{W F}(t)$ and $P_{T B}(t)$ with $t$ respectively to obtain the power generation of wind turbine and water turbine within A certain period of time. The annual generating capacity of a jointly operated power station can be expressed as:

$$
P_{W-P}=\int_{0}^{8760}\left[P_{W F}(t)+P_{T B}(t)\right] d t
$$

The total annual cost of power generation of the wind-storage combined operation power station is estimated by Equation (5), then the estimated cost model of unit electricity generation is as follows:

$$
C_{U E}=\frac{C_{\text {total }}}{P_{W-P}}=\frac{C_{E X}+\left[\left(I_{W P}+I_{P S}-I_{L C}\right) \times(1-\alpha) / M\right] \times(1+\gamma)}{\int_{0}^{8760}\left[P_{W F}(t)+P_{T B}(t)\right] d t}
$$

\section{Conclusion}

The cost per unit of electricity is an important basis to judge the feasibility and economy of the scheme in the early stage of the project. In this paper, an estimation model of cost per unit of electricity generation cost is established based on the analysis of the investment cost and annual power generation of the wind-storage combined power station.

From the perspective of investment estimation, this paper analyses in detail the composition of the total investment cost of the project and the estimation method 
of each component. When calculating the annual power generation of the combined power station, the operation mode to support the load system by the combined power station and conventional power plant in the system is determined at first, and then the six operation modes proposed by European scholars are analysed in detail, it can be concluded that: wind turbines and water turbines generate electricity in all operating modes. Under different operation mode, the calculation method of output power is the same. Integrating the generation power over time can obtain the annual power generation of the combined operation power station. The ratio of annual investment cost to annual power generation is the cost per unit of electricity.

\section{References}

1. LU Y. Pumped Storage Power Station is the Best Peak Regulating Power Source of Wind Power. China Energy News. (2010).

2. WANG N, LIU Y. Construction Project Cost Control and Case Study. Wuhan University of Technology Press, Wuhan. (2005).

3. YANG Z. Research on Multi-Source Joint Grid Connected Scheduling Strategy with CSP Based on Cost Optimization. Northeast Electric Power University, Jilin. (2019).

4. ZHANG L, YIN M, BU J, SONG K, ZOU Y. A Joint Optimal Operation Model of Wind Farms and Pumped Storage Units Based on Cost-Benefit Analysis, Power System Technology, 39(12):33863392. (2015).

5. LIU D, TAN Z, WANG F. Simulation Research on Wind Power-Pumped Storage Joint Operation System. Hydroelectric Energy Science., 06: 39-42. (2006).

6. C.Bueno, J.A.Carta. Technical-economic analysis of wind-powered pumped hydrostorage systems. (Part I: model development).Solar Energy, 78(3):382-395. (2005).

7. C.Bueno, J.A.Carta. Technical-economic analysis of wind-powered pumped hydrostorage systems. (Part II: model application to the island of El Hierro).Solar Energy, 78(3):396-405. (2005). 